\title{
Investigation of Different Materials as Acetone Sensors for Application in Type-1 Diabetes Diagnosis
}

\author{
Md Razuan Hossain ${ }^{1}$, Qifeng Zhang ${ }^{1,2}$, Michael Johnson ${ }^{1,2}$, Obinna Ama ${ }^{1}$ and Danling Wang*1,2 \\ ${ }^{1}$ Department of Electrical and Computer Engineering, USA \\ ${ }^{2}$ Materials and Nanotechnology Program, USA \\ *Corresponding author: Danling Wang, Assistant Professor, Department of Electrical and Computer Engineering, USA
}

\section{ARTICLE INFO}

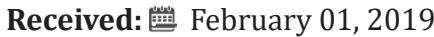

Published: 㗀 February 20, 2019

Citation: Md Razuan H, Qifeng Z, Michael J, Obinna A, Danling W. Investigation of Different Materials as Acetone Sensors for Application in Type-1 Diabetes Diagnosis. Biomed J Sci \& Tech Res 14(5)-2019. BJSTR. MS.ID.002619.

Keywords: Diabetes; Biomarker; Breath Acetone; $\mathrm{K}_{2} \mathrm{~W}_{7} \mathrm{O}_{22}$; Non-Invasive; Blood Glucose; Semiconducting Material
ABSTRACT

Diabetes, one of the most rapidly-growing chronic diseases in the world, is overall relative expensive on both diagnosis and monitoring. Breath acetone has proven to be a biomarker of diabetes which is a metabolite with a strong correlation with blood glucose. Measuring the concentration of acetone in exhaled breath can provide a non-invasive, low risk of infection, low cost, and convenient way to screen diabetics at the early stage and daily monitor the health condition of diabetics. Several materials have been investigated for their ability to detect of breath acetone. The preliminary results show that nanostructured $\mathrm{K}_{2} \mathrm{~W}_{7} \mathrm{O}_{22}$ (KWO), a new functional semiconducting material, synthesized by hydrothermal method, can effectively detect breath acetone at room temperature. This paper emphasizes that the sensing performance of KWO on breath acetone. In addition, a comparison between KWO with other materials for application in sensing acetone is discussed.

\section{Introduction}

It is necessary to detect diseases at an early stage since this may minimize harmful effects on the human body. Diabetes, as the 7th leading cause of death in the United States, is a disease that is characterized by a heterogeneous group of blood disorders and can be indicated by high Blood Glucose (BG) levels [1,2]. Based on 2017 statistics, about 30.3 million people in the U.S. have diabetes, which is about $9.4 \%$ of the U.S. population [3]. Among those 30.3 million people, there were 23.1 million people diagnosed as diabetics. The remaining 7.2 million people were not diagnosed due to complicated reasons. One of major concerns is due to expensive and complicated diagnosing process [3]. So, it is necessary to provide an affordable, reliable, and convenient method which makes the segment of population to obtain diagnosis and treatment in time. There are many ways to screen diabetes in the early stage, such as the A1C test (a blood test that provides information about blood glucose levels) [4], the Fasting Plasma Glucose Test (FPG), and the Oral Glucose Tolerance Test (OGTT) [5]. These tests are accurate but inconvenient with relatively high cost.
Most recently, detection of Volatile Organic Compounds (VOCs) in exhaled breath has caused a lot attention since some of VOCs are found closely related to human health [6]. Therefore, some Volatile Organic Compounds (VOCs) have been identified as biomarkers for different diseases, such as carbon disulphide for Schizophrenia $[7,8]$, isovaleric acid for urinary tract infections [9], dodecane, 4-methyl decane, and undecane for melanoma [10]. Besides the compounds listed above, breath acetone, has also received attention due to a good correlation between the concentration of acetone in exhaled breath and blood sugar level in human body [11,12]. This is because metabolic disorders can affect the concentration of acetone in human breath [13-17]. So, breath acetone can be used as a biomarker to diagnose diabetes. By measuring the concentration of acetone in human breath $[17,18]$, it could provide a convenient, inexpensive, and non-invasive way for early-stage diabetes diagnosis and health condition monitoring. Generally, concentration of exhaled breath acetone is usually in the range of 0.3-0.9 Parts-Per-Million (ppm) for healthy humans and above 
$1.8 \mathrm{ppm}$ for diabetic patients [18]. While, acetone concentration between $0.9 \mathrm{ppm}$ to $1.8 \mathrm{ppm}$ is considered as prediabetes. Thus, a breath analyzer to detect the concentration of breath acetone below $0.9 \mathrm{ppm}$ could be an efficient way of screening diabetes at an early stage.

The nanostructured $\mathrm{K}_{2} \mathrm{~W}_{7} \mathrm{O}_{22}$ (KWO) material [19], recently developed in our research group, shows a sensitive response to acetone at room temperature. The preliminary results indicate that such sensitive response is mainly due to the porous structure and excellent ferroelectric property [20] of KWO material. This could cause a strong surface interaction and effective charge transfer between sensing molecules and KWO. In this paper, we will briefly discuss the sensing performance of KWO to detect acetone. In the meanwhile, we choose other four materials: Pt-InN [13], Polypyrrole (PPy)-WO $\mathrm{WO}_{3}$ [21], Ni/InGaN/GaN [22], and $\mathrm{Pd} / \mathrm{TiO}_{2} / \mathrm{Si}$ [23], which all show good response to acetone. The main purpose of this paper is to study those five materials with different sensing conditions for their potential application in diabetes diagnosis and monitoring [24,25].

\section{Experimental Section}

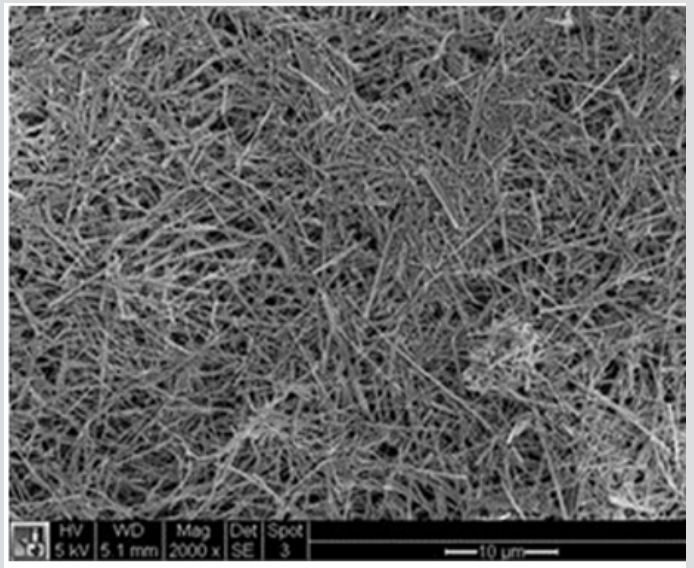

Figure 1: SEM image of the interconnected 3D mesh structure of a KWO thin film.

In this section, a brief description of KWO synthesis will be presented. In addition, KWO film preparation, equipment and procedure of a chemiresistive sensor based on KWO to detect acetone are discussed. The single crystalline nanostructured KWO was synthesized by a hydrothermal technique $[26,27]$. Briefly, a precursor solution containing $\mathrm{Na}_{2} \mathrm{WO}_{4}$, oxalic acid, $\mathrm{K}_{2} \mathrm{SO}_{4}$, and HCL is made. This solution is then put into a $30 \mathrm{~mL}$ autoclave for synthesis. KWO samples were grown at $225^{\circ} \mathrm{C}$ for 24 hours. The as-synthesized nanostructured KWO were dispersed in ethanol to form a suspension and drop-casted on glass substrates to form a thin film with about $10 \mu \mathrm{m}$ in thickness. The morphology of the KWO film was studied with scanning electron microscopy (SEM) (Figure 1) and the film shows a highly porous structure made of a three-dimensional mesh of randomly orientated and interconnected nanorods.
The average length of the nanorods is about several micron and the diameter of nanorod is about $10 \mathrm{~nm}$, which are adjustable through synthesis conditions. Electric contact pads made of gold are sputtering deposition onto the thin film. The sensing response of KWO by exposing acetone is determined by measuring its resistance between the metal contacts with an electrometer (Keithley 6514). More information regarding KWO to detect acetone can be found from our published literatures [19,24,25].

\section{Results}

This section mainly discusses the sensing performance based on five materials towards acetone detection under different circumstances (temperature, concentrations, response time etc.)

\section{KWO Material}

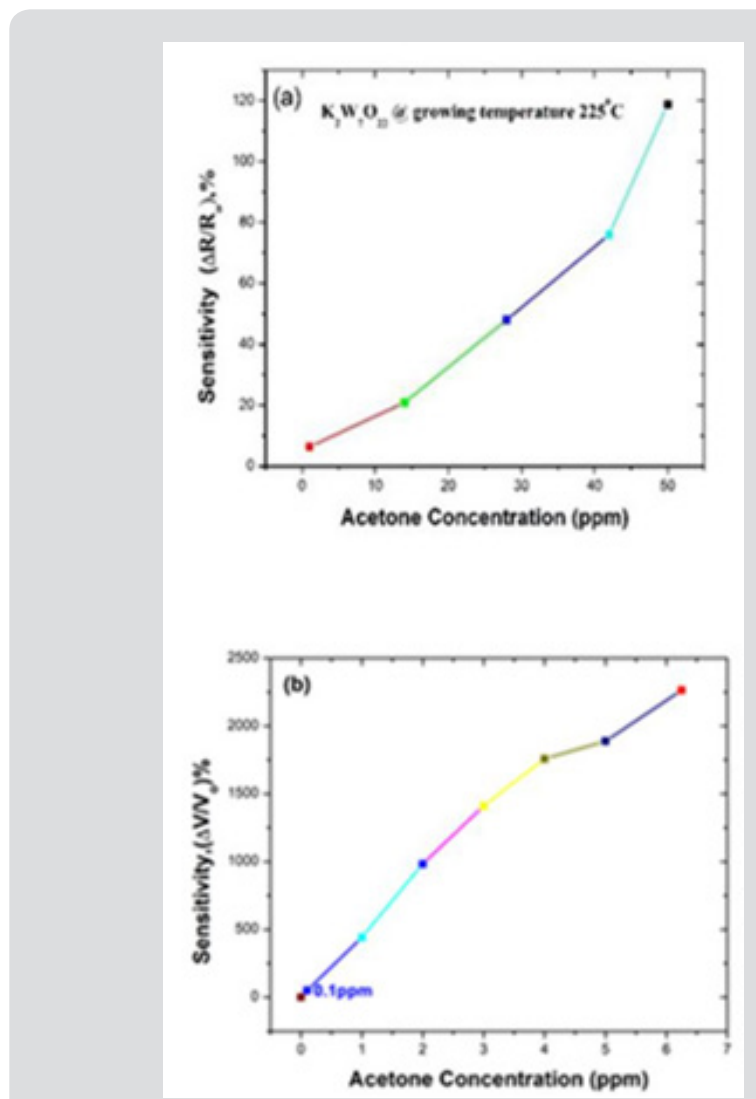

Figure 2: Response of $\mathrm{KWO}$ sensor grown in $225^{\circ} \mathrm{C}$ acetone with $\mathrm{RH} \sim 30 \%$ at room temperature. (a) Sensing response to acetone with concentration from 0 to $50 \mathrm{ppm}$; (b) sensing to acetone with concentration from 0 to $6.25 \mathrm{ppm}$.

The material KWO (made in our group) is grown with thermal temperature at $225^{\circ} \mathrm{C}$. Figure 2a shows the response of KWO to detect acetone with variable concentration from $0 \mathrm{ppm}$ to 50 ppm at room temperature with $\mathrm{RH} \sim 30 \%$. It was observed that the sensitivity is only $6.34 \%$ while acetone concentration is about $0.125 \mathrm{ppm}$. It is not optimal considering its potential clinic application. A much lower detection limit of acetone is needed. After we modified the signal collecting circuits, the KWO sensor can be used to detect quite low concentration of acetone, for example, 
$0.125 \mathrm{ppm}$ with decent sensitivity. Figure $2 \mathrm{~b}$ shows the response to acetone which concentration is from 0 to $6.25 \mathrm{ppm}$. The results indicated a detection limit can be up to $0.1 \mathrm{ppm}$ with sensitivity around $50.75 \%$. It is about 8 times higher than the sensitivity of $6.34 \%$ based on our previous sensing system. The results revealed that KWO is a promising sensing material to detect acetone.

\section{PPy-WO}

The sensing response of $\mathrm{PPy}-\mathrm{WO}_{3}(20 \%)$ hybrid nanocomposite sensor [21] to different concentration of acetone at operating temperature $90^{\circ} \mathrm{C}$ has been redrawn in Figure 3 (The graph is based on the data of Figure 2(b) in article [21]). As indicated in the Figure, the sensitivity of this sensor is quite low, which is less than $0.5 \%$ even when acetone concentration is $200 \mathrm{ppm}$.

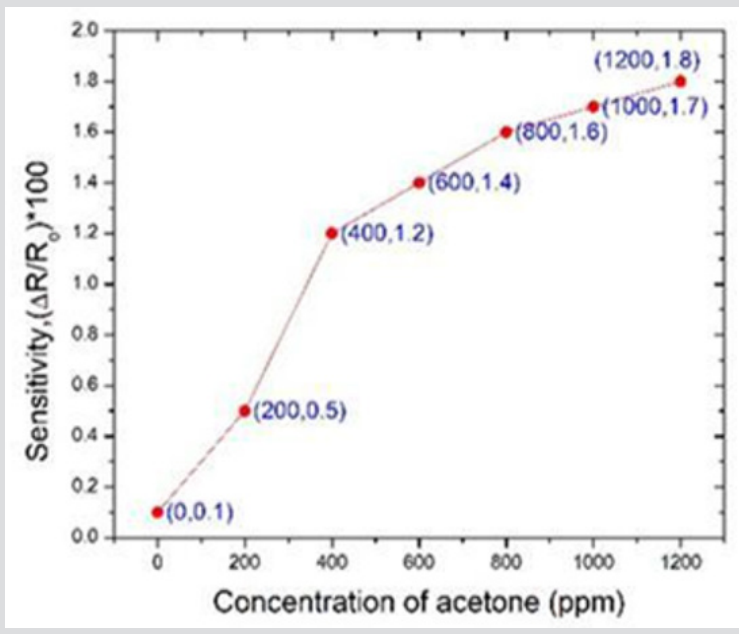

Figure 3: Response behavior of $\mathrm{PPy}-\mathrm{WO}_{3}(20 \%)$ hybrid nanocomposite sensor [21] at different concentration of acetone at $90^{\circ} \mathrm{C}$.

\section{InN and Pt-InN}

Kun Wei, had studied bare InN and Pt-InN sensors to observe the response of acetone gas at different operating temperatures $\left(150^{\circ} \mathrm{C}, 175^{\circ} \mathrm{C}\right.$, and $\left.200^{\circ} \mathrm{C}\right)$. A comparison of sensitivity of both the sensors from $0.4 \mathrm{ppm}$ to $20 \mathrm{ppm}$ at operating temperature $200^{\circ} \mathrm{C}$ is redrawn in Figure 4 (The data has taken from the graph of $(2 \mathrm{~b}$ and $4 b$ ) in article [13]). It was found that Pt-InN (red line) shows higher more sensitive to acetone compared to bare InN (blue line). The sensitivity of $4.95 \%$ was observed on Pt-InN while was almost two times higher than the sensitivity of bare InN, $2.4 \%$ while acetone concentration was $0.4 \mathrm{ppm}$.

\section{Nanocrystalline $\mathrm{TiO}_{2}$}

In article [23], nanocrystalline $\mathrm{TiO}_{2}$ based Metal Insulator Semiconductor (MIS) was used as the sensing material to detect different concentrations of acetone $(10,50,100 \mathrm{ppm})$ from $100^{\circ} \mathrm{C}$ to $200^{\circ} \mathrm{C}$. Figure 5 shows the response magnitude of $\mathrm{TiO}_{2}$ sensor for $10,50,100 \mathrm{ppm}$ at three different temperatures (The data of Figure 4 has taken from the graph (6) in article [23]). The overall sensivities of $\mathrm{TiO}_{2}$ to acetone are no more than $5 \%$. While, they observed that the sensing response can be improved a little bit while sensors were operating at higher temperature.

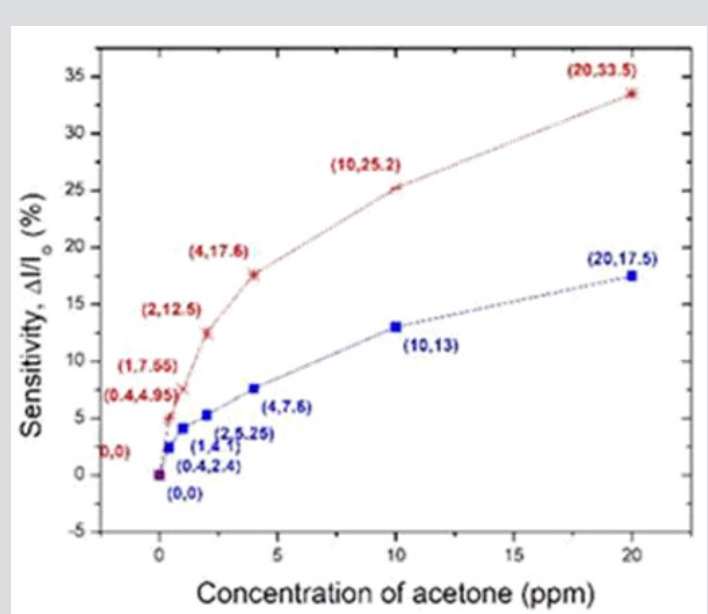

Figure 4: Comparison of sensitivity between Bare $\mathrm{InN}$ (blue) and Pt-InN (red) [13] to trace acetone from 0.4 to 20 ppm at $200^{\circ} \mathrm{C}$.

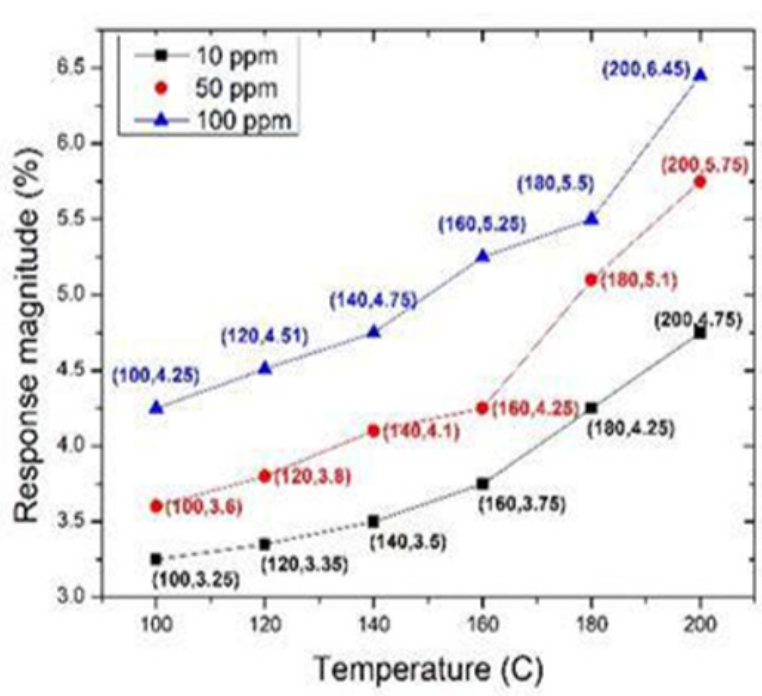

Figure 5: Response magnitude vs. temperature characteristics of $\mathrm{TiO}_{2}$ sensor in 10, 50 and 100 ppm acetone [28].

\section{$\mathrm{Ni} / \mathrm{InGaN} / \mathrm{GaN}$}

In article [22], $\mathrm{Ni} / \mathrm{InGaN} / \mathrm{GaN}$ heterostructure resistive sensor is used to detect acetone concentration from $100-400 \mathrm{ppm}$ at fixed operating temperature $100^{\circ} \mathrm{C}$. They measured the sensitivity in terms of ratio of current in presence of acetone vapor (Iac) to current in air (Iair). Figure 6 shows the sensitivity of the heterostructure sensor has a slight increase while the acetone concentration is higher, $1.034 \%$ on 400 ppm of acetone and $1.022 \%$ on 100 ppm of acetone (The data of Figure 6 has taken from the graph 4(a) of article [22]). 


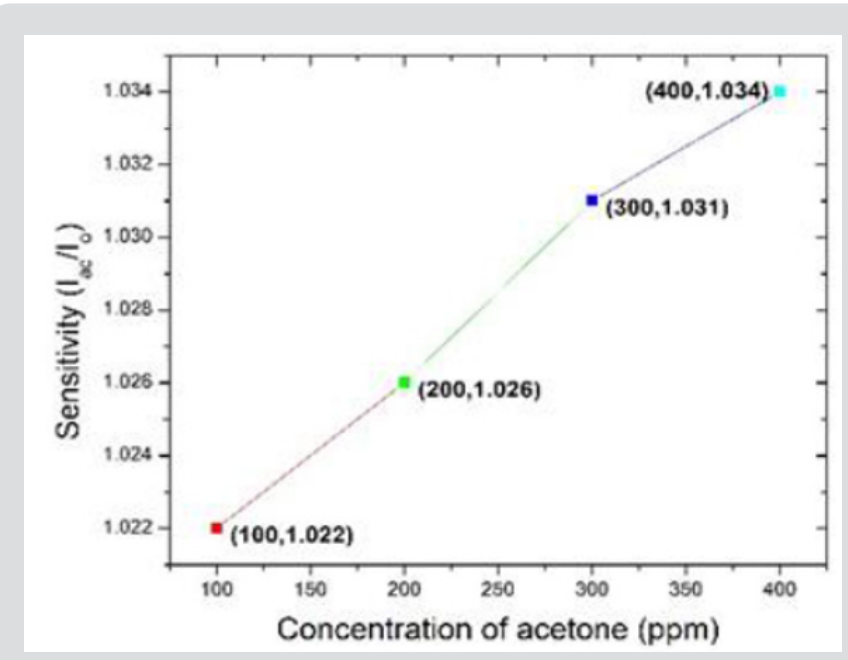

Figure 6: Sensitivity of $\mathrm{Ni} / \mathrm{InGaN} / \mathrm{GaN}$ heterostructure sensor for acetone concentration $100-400 \mathrm{ppm}$ at operating temperature $373 \mathrm{~K}\left(100^{\circ} \mathrm{C}\right)$ [22].

\section{Discussion}

Detection limit, sensitivity, and response time [28] are the most important parameters for evaluating the sensing performance of sensors. Detection limit is defined as the lowest quantity of substance that can be distinguished from the absence of that substance with a 99\% confidence level [29]. Sensitivity is defined as the variation in current ratio for specific gas concentration. If $R_{\text {gas }}$ and $R_{\text {air }}$ are the resistance values of the sensor, then the sensitivity, $S[13]$ is,

$$
S=\frac{R_{\text {gas }}-R_{\text {air }}}{R_{\text {air }}} \times 100 \%
$$

Response time [13] measures the time it takes for the relative current to change from $10 \%$ to $90 \%$ of the total current. In addition, sensitivity and response time can be represented in terms of voltage or current. Considering the purpose of a breath analyzer is to be used in a disease diagnosis fast response, quick recovery, high sensitivity, and low detection limits (a range of ppb to ppm) are all important factors. Since doping, operating temperature, configuration, and surface modification are usually used to optimize these parameters, sensing performance is relying on them as well. Below, the sensing performances based on five materials, $\mathrm{PPy}-\mathrm{WO}_{3}$, InN, Pd/ $\mathrm{TiO}_{2} / \mathrm{p}-\mathrm{Si}, \mathrm{Ni} / \mathrm{InGaN} / \mathrm{GaN}$ and KWO, with different doping, surface modification, and operating conditions have been discussed and summarized.

\section{PPy-WO 3 Hybrid Nanocomposites Sensor}

As discussed earlier (Figure 3), Hoda et al. [21] investigated how a Polypyrrole (PPy)- $\mathrm{WO}_{3}$ hybrid nanocomposite with variable percentages of $\mathrm{WO}_{3}$ nanoparticles dispersed in a PPy matrix can be used as the sensing material to detect acetone. Their result showed that the $\mathrm{PPy}-\mathrm{WO}_{3}(20 \%)$ hybrid nanocomposite has a fast response $(<5 \mathrm{~s})$ to acetone vapor at an operating temperature of $90^{\circ} \mathrm{C}$. Also, they observed the detection limit for $\mathrm{PPy}^{-\mathrm{WO}_{3}}(20 \%)$ was $0.37 \mathrm{ppm}$.

\section{InN Gas Sensor}

Kun Wei, investigated [13] how well an Indium Nitride (InN) gas sensor having a thickness of $10 \mathrm{~nm}$ was able to detect acetone down to $0.4 \mathrm{ppm}$ (Figure 4) at different operating temperatures: $150^{\circ} \mathrm{C}, 175^{\circ} \mathrm{C}$, and $200^{\circ} \mathrm{C}$. They used platinum as a catalyst, to increase current signals and reduce response times and found that Pt-InN has better response than Bare InN.

\section{$\mathrm{Pd} / \mathrm{TiO}_{2} / \mathrm{p}$-Si MIS Sensor}

Hazra, introduced a nanocrystalline $\mathrm{TiO}_{2}$ based sensor [23] that can detect acetone from 10 to $100 \mathrm{ppm}$ (Figure 5). They prepared a $\mathrm{TiO}_{2}$ sensing layer-based MIS device structure that was operated between 100 to $200 \mathrm{oC}$. They observed the response time was 7.7 sec at $100^{\circ} \mathrm{C}$ for $10 \mathrm{ppm}$. Also, the sensitivity is better while the sensor worked at higher temperature.

\section{$\mathrm{Ni} /$ InGaN/GaN Heterostructure Sensor}

Subhasis, developed a [22] Ni/InGaN/GaN based heterostructure resistive gas sensor (Figure 6). They exposed this sensor to $100 \mathrm{ppm}$ acetone with an operating of bias $0.4 \mathrm{~V}$ at $373 \mathrm{~K}\left(100^{\circ} \mathrm{C}\right)$. In their analysis, they observed the response time of $\sim 7.6-8.4 \mathrm{sec}-$ ond and a corresponding recovery time of $\sim 4.5-19.1$ second.

\section{KWO Sensor}

The KWO sensor, as shown in Figure 2, can detect acetone concentration up to $0.1 \mathrm{ppm}$ at room temperature $\left(25^{\circ} \mathrm{C}\right)$ based on a chemiresisive sensing mechanism. The KWO nanorods exhibits excellent sensing performance to acetone [31].

As a summary, Table 1 describe the sensing performances based above materials for application in acetone detection. Considering the application purpose - a tool of early-stage diabetes diagnosis, it requires that the sensor should have the detection limit as low as $0.9 \mathrm{ppm}$. As shown in Table 1, among these five materials, the detection limits of PPy- $\mathrm{WO}_{3}(20 \%), \mathrm{Pt}-\mathrm{InN}$, and $\mathrm{K}_{2} \mathrm{~W}_{7} \mathrm{O}_{22}$, are $0.37 \mathrm{ppm}, 0.4 \mathrm{ppm}$, and $0.1 \mathrm{ppm}$ respectively. The $\mathrm{PPy}-\mathrm{WO}_{3}(20 \%)$ material-based sensor has the lowest detection limit of $0.37 \mathrm{ppm}$. However, its sensitivity is very small, only about $3.34 \times 10^{-3} \%$ with concentrations of acetone from $19 \mathrm{ppm}$ to $316 \mathrm{ppm}$. So, the PPy$\mathrm{WO}_{3}(20 \%)$ material would not be a good option for breath acetone detection due to such poor sensitivity. The Ni/InGaN/GaN based Hetero-structure sensor ( $7.6 \& 2 \mathrm{sec}$ ) shows a faster response and recovery time at $100 \mathrm{ppm}$ of acetone as compared to $\mathrm{Pd} / \mathrm{TiO}_{2} / \mathrm{p}-\mathrm{Si}$ MIS sensor (16 \& $30 \mathrm{sec}$ ). However, a lowest detection limit of 100 ppm is far too high to detect the threshold of acetone, $0.9 \mathrm{ppm}$. The MIS sensor can get the detection limit down to $10 \mathrm{ppm}$ but still too high to be used for the detection of breath acetone in diabetics. Due to these limitations, these two sensors cannot be a choice for breath acetone detection in diabetes diagnosis and monitoring. Considering the detection limit, within these materials, only Pt-InN and KWO do have the capability of detecting concentration of acetone less than $1.0 \mathrm{ppm}$ with relatively good sensitivity. 
Table 1: Data analysis of five different materials to detect acetone.

\begin{tabular}{|c|c|c|c|c|c|}
\hline Materials & Device structure & $\mathbf{t}(\mathbf{S})$ & OT* (OC) & $\mathbf{S}(\mathbf{\%})$ & Detection Limit (PPM) \\
\hline $\begin{array}{c}\mathrm{PPy}-\mathrm{WO}_{3} \\
-20 \%\end{array}$ & Hybrid Nanocomposite & NA & 90 & $3.34 \times 10^{-4}$ & 0.37 \\
\hline $\mathrm{Pt}-\mathrm{InN}$ & Ultra-thin FET & NA & 200 & 5.07 & 0.4 \\
\hline $\mathrm{K}_{2} \mathrm{~W}_{7} \mathrm{O}_{22}$ & Chemiresistor & 12.5 & 25 & 50.75 & 0.1 \\
\hline $\mathrm{Pd} / \mathrm{TiO}_{2} / \mathrm{p}-\mathrm{Si}$ & MIS & $\sim 15$ & 100 & 16 & 10 \\
\hline $\mathrm{Ni} / \mathrm{InGaN} / \mathrm{GaN}$ & Heterostructure & $\sim 7.6$ & 100 & 1.021 & 100 \\
\hline
\end{tabular}

*OT: Operating Temperature

NA: Not Available

т: response time

In Figure 7, we further compared the sensing response to acetone only focusing on the materials of KWO and the Pt-InN (This graph is based on data in Figures 4b [13] in black and 3a [19] in red). Figure 7 shows that the KWO based chemiresistive sensor demonstrates much higher sensitivity than the Pt-InN based sensor has, while acetone concentrations vary from 0 to $20 \mathrm{ppm}$. In addition, the KWO sensor can operate at room temperature without requiring any external source of heat, while Pt-InN sensor needs to work under $200^{\circ} \mathrm{C}$. All these indicate that the nanostructured KWO based acetone sensor is an optimal device with less power consumption and higher sensitivity.

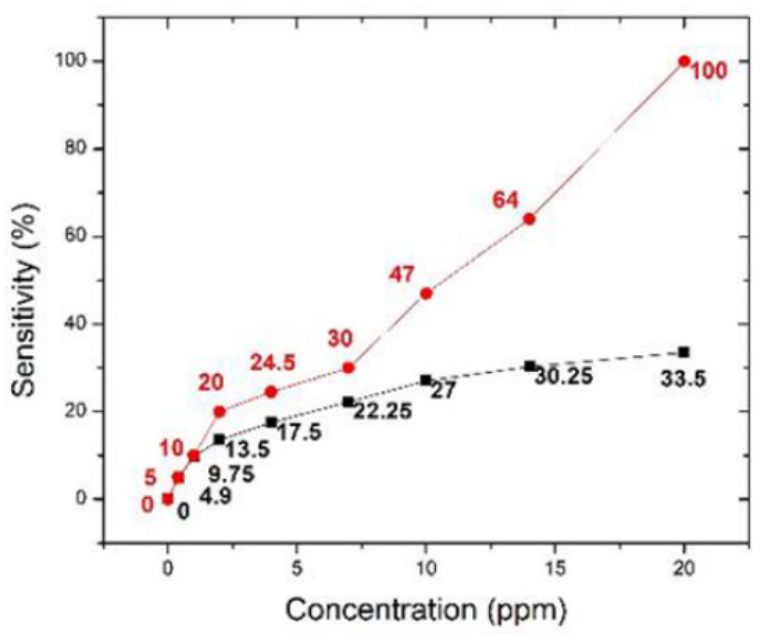

Figure 7: Comparison between Pt-InN (black) and KWO (red) sensor in terms of sensitivity.

Also, the KWO sensor device is simple and easy to be made [12] due to its chemiresistive sensing mechanism. The main reason why nanostructured $\mathrm{K}_{2} \mathrm{~W}_{7} \mathrm{O}_{22}$ shows much better sensing performance on the detection of acetone can be explained by its high surface to volume ratio due to the nanoscale and porous structure and the specific material property - the room-temperature ferroelectric property of KWO (detailed discussion can be found in our published paper [24]). All of these properties result in an efficient surface interaction between KWO and acetone. While, the sensing processes based on the other four acetone sensors, all need to operate at an evaluated temperatures $\left(>100^{\circ} \mathrm{C}\right)$. This is mainly due to a surface oxidation reaction between the materials and acetone $[30,31]$. In a word, according to above discussion, it reveals that the material and structure properties play the most important role in detecting acetone. Since as-fabricated nanostructured KWO has a room-temperature ferroelectric property and high surface area $[19,24]$, it provides an effective surface to sensitively interact with high dipole moment molecules such as acetone even at a low operating temperature.

\section{Conclusion}

We have studied and compared five different sensing materials with different operating conditions to detect acetone, the breath biomarker of diabetes. Within these materials, the nanostructured KWO showed the best response to acetone, which can detect the lowest concentration of acetone up to $0.1 \mathrm{ppm}$ with fast response only around $12 \mathrm{~s}$ at room temperature. As a completely newly synthesized nanostructured material, this unique material and structure property - room temperature ferroelectric property and high surface area with porous structure provide a favourable charge transfer and diffusion channel between KWO and acetone, which causes a strong interaction with acetone. In a word, KWO proves to be a promising material with great potential for diabetes diagnosis and monitoring under practical applications.

\section{Acknowledgement}

This work is supported by Sanford Health - NDSU Research Seed Grant, FAR0028165; Offerdahl Seed Grant; NDSU Centennial Endowment Award, FAR0029296; and ND NASA EPSCoR research grant, FAR0030154. We also wish to acknowledge the NDSU Core Research Facilities for providing access to microfabrication tools and materials characterization instruments.

\section{References}

1. C Wang, A Mbi, M Shepherd (2010) A Study on Breath Acetone in Diabetic Patients Using a Cavity Ringdown Breath Analyzer: Exploring Correlations of Breath Acetone with Blood Glucose and Glycohemoglobin A1C. IEEE Sen J 10(1): 54-63.

2. MI Harris (1995) Diabetes in America, ( $2^{\text {nd }}$ edn) Bethesda, Maryland, USA. 
3. (2017) National Diabetes Statistics Report.

4. (2018) The A1C Test \& Diabetes.

5. (2018) Diagnosing Diabetes and Learning about Prediabetes.

6. BL Costello, A Amann, H Al Kateb, C Flynn, W Filipiak, et al. (2014) A review of the volatiles from the healthy human body. J of Breath Res 8(1): 014001.

7. M Phillips, M Sabas, J Greenberg (1993) Increased pentane and carbon disulfide in the breath of patients with schizophrenia. J of Clinic Path 46(9): 861-864.

8. M Phillips, M Sabas, J Greenberg (1995) Volatile organic compounds in the breath of patients with schizophrenia. 48(5): 466-469.

9. A Amann, D Smith (2013) Volatile biomarkers, ( $1^{\text {st }}$ edn.), Newnes.

10. (2012) Compositions, methods and kits for detecting melanoma and margins of melanoma. US.

11. A Rydosz (2015) A Negative Correlation Between Blood Glucose and Acetone Measured in Healthy and Type 1 Diabetes Mellitus Patient Breath. J of Diabetes Sci and Tech 9(4): 881-884.

12. (2018) Chemiresistors.

13. KW Kao, MC Hsu, YH Chang, S Gwo, JA Yeh (2012) A sub-ppm acetone gas sensor for diabetes detection using $10 \mathrm{~nm}$ thick ultrathin InN FETs. Sensors 12(6): 7157-7168.

14. Q Zhang, P Wang, J Li, X Gao (2000) Diagnosis of diabetes by image detection of breath using gas-sensitive laps. Biosens Bioelectron 15 (56): 249-256.

15. S Tjoa, P Fennessey (1991) The identification of trimethylamine excess in man: quantitative analysis and biochemical origins. Anal Biochem 197(1): 77-82.

16. K Moorhead, D Lee, J Chase, AR Moot, KM Ledingham, et al. (2008) Classifying algorithms for SIFT-MS technology and medical diagnosis. Comput Meth Progr Biomed 89 (3): 226-238.

17. P Mayes, R Murray, D Granner, V Rodwell (2000) Harper's Biochemistry, McGraw-Hill Companies Inc. New York, NY, USA.

18. C Deng, J Zhang, X Yu, W Zhang,X Zhang (2004) Determination of acetone in human breath by gas chromatography-mass spectrometry and solidphase microextraction with on-fiber derivatization. J Chromatogr B 810(2): 269-275

\section{ISSN: 2574-1241}

DOI: 10.26717/BJSTR.2019.14.002619

Danling Wang. Biomed J Sci \& Tech Res

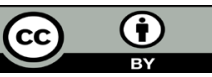

This work is licensed under Creative Commons Attribution 4.0 License

Submission Link: https://biomedres.us/submit-manuscript.php
19. D Wang, Q Zhang (2016) Room temperature acetone sensor based on nanostructured K2W7022, presented in IEEE Sensors 2016, FL, USA.

20. (2018) Structure and properties of ferroelectric materials.

21. H Jamalabadi, N Alizadeh (2017) Enhanced Low-Temperature Response of PPy-WO3 Hybrid Nanocomposite Based Gas Sensor Deposited by Electrospinning Method For Selective and Sensitive Acetone Detection. IEEE Sens J 17 (8): 2322-2328.

22. D Subhashis, A Bag, R Kumar, D Biswas (2017) Fast Response (7.6s) Acetone Sensing by InGaN/GaN on Si (111) at 373 K. IEEE-EDL 38(3): 383-386.

23. A Hazra, B Bhowmik, K Dutta, P Bhattacharyya (2013) Low Temperature Low ppm Acetone Detection by $\mathrm{Pd} / \mathrm{TiO} 2 / \mathrm{p}-\mathrm{SiMetal}$-InsulatorSemiconductor Devices. $7^{\text {th }}$ International Conference on Sensing Technology (ICST 2013) 3(5): 396-400.

24. D Wang, Q Zhang, MR Hossain, M Johnson (2018) High Sensitive Breath Sensor Based on Nanostructured K2W7022 for Detection of Type 1 Diabetes. IEEE Sens J 18(11): 4399-4404.

25. MR Hossain, Q Zhang, M Johnson, D Wang (2017) Investigation of humidity cross interference effect on acetone breath sensor based on nanostructured K2W7022. Eng Press 1(1): 30-34.

26. M Yoshimura, K Byrappa (2008) Hydrothermal processing of materials: Past, present and future, J of Mat Sci 43(7): 2085-2103.

27. LF Lopes, FM Pontes, LO Garcia, DSL Pontes, D Padovani, et al. (2018) Silver-controlled evolution of morphological, structural, and optical properties of three-dimensional hierarchical WO3 structures synthesized from hydrothermal method. J of All and Comp 736(5): 143151.

28. (2018) Chemical sensors.

29. (2018) Detection limit.

30. N Barsan, U Weimar (2001) Conduction Model of Metal Oxide Gas Sensors. J of Electroc 7(3): 143-167.

31. MR Hossain, Q Zhang, M Johnson, D Wang (2018) Highly Sensitive Room-Temperature Sensor Based on Nanostructured K2W7022 for Application in the Non-Invasive Diagnosis of Diabetes. Sensors 18(11): 3703-3712.

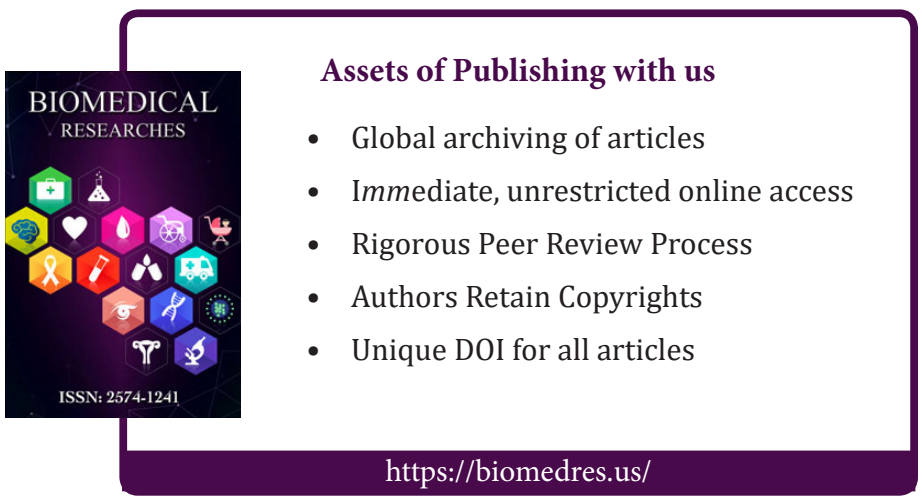

Copyright@ Danling Wang| Biomed J Sci \& Tech Res| BJSTR. MS.ID.002619. 